\title{
Chemical Structure of Si-0 in Silica Fume from Ferrosilicon Production and Its Reactivity in Alkali Dissolution
}

\author{
Yiwei ZHONG, Xinle QIU, Jintao GAO* and Zhancheng GUO \\ State Key Laboratory of Advanced Metallurgy, University of Science and Technology Beijing, Beijing, 100083 P. R. China. \\ (Received on July 21, 2018; accepted on January 10, 2019; J-STAGE Advance published date: January \\ $31,2019)$
}

\begin{abstract}
As an environmentally hazardous waste, silica fume was considered as a potential alternative for cement and $\mathrm{SiO}_{2}$ production. The structure of $\mathrm{Si}-\mathrm{O}$ was highly relevant to the reactivity of $\mathrm{Si}$ conversion for efficient utilization. In this study, the characteristic and chemical structure of Si-O in silica fume were characterized by X-ray photoelectron spectroscopy (XPS) and Fourier transform infrared (FTIR). Deconvolution of XPS and FTIR spectra into elementary profiles was carried out to analyze the structural components. As a result, the valence state, bonding structure and elementary unit in the Si-O network of silica fume were determined. Then, the reactivity silica fume with alkali solution was studied involving the effects of $\mathrm{NaOH}$ concentration and temperature. The staged kinetics behavior was associated with the structure of $\mathrm{Si}-\mathrm{O}$ bonds, and the activation energies were determined. The results thus provided fundamental information for the utilization of silica fume for $\mathrm{SiO}_{2}$ production and geopolymer.
\end{abstract}

KEY WORDS: silica fume; ferrosilicon; industrial solid waste; Si-O structure; alkali dissolution; staged kinetics.

\section{Introduction}

With the rapid development of the steelmaking industry, there is a great demand for ferrosilicon used as deoxidizing agent. ${ }^{1)}$ Ferrosilicon is produced by carbothermal reduction of silica and iron oxide with carbon in an electric arc furnace. During the production of ferrosilicon, a large amount of silica fume was generated as a type of dust waste. ${ }^{2)}$ It was estimated that 2 million tons/year of silica fume was generated in China. ${ }^{3)}$ Silica fume is a highly effective pozzolanic material due to its large specific surface area and high amorphous silica content. ${ }^{4,5)}$ It has been used in geo-materials by combining with fly ash of coal combustion as a partial substitute of Portland cement, showing several advantages in terms of mechanical performance and durability. ${ }^{6-8)}$ Silica fume of sub-micro size is an active component which can react with $\mathrm{Ca}(\mathrm{OH})_{2}$ to produce the calcium silicate hydrate $\mathrm{C}-\mathrm{S}-\mathrm{H}$ (gel) phase. In the alkali-activated reaction, silicate reactive materials are rapidly dissolved into alkaline solution to form free $\mathrm{SiO} 4$ tetrahedral units. During the polycondensation reaction, the tetrahedral units are linked in an alternate manner to form amorphous geopolymers, and $\mathrm{OH}^{-}$in $\mathrm{Ca}(\mathrm{OH})_{2}$ is released to afford alkali for the dissolution of $-\mathrm{Si}-\mathrm{O}-\mathrm{Si}-$ structure. $^{9-11)}$

$$
\begin{aligned}
& -\mathrm{Si}-\mathrm{O}-\mathrm{Si}-+\mathrm{OH}^{-} \rightarrow \mathrm{SiO}_{3}{ }^{2-} \\
& \mathrm{SiO}_{3}{ }^{2-}+\mathrm{Ca}(\mathrm{OH})_{2} \rightarrow \mathrm{CaSiO}_{3} \downarrow+\mathrm{OH}^{-}
\end{aligned}
$$

\footnotetext{
* Corresponding author: E-mail: ft4314761@163.com DOI: https://doi.org/10.2355/isijinternational.ISIJINT-2018-516
}

The addition of silica fume can modify the microstructure of hydrated pastes due to the formation of denser and lower-porosity, compact $\mathrm{C}-\mathrm{S}-\mathrm{H} .{ }^{11,12)}$ Silica fume also can be recycled as $\mathrm{Si}$ resource for $\mathrm{Na}_{2} \mathrm{SO}_{3}$ and $\mathrm{SiO}_{2}$ material production. ${ }^{13-15)}$ Ultrafine hydrophobic precipitated silica (nano-silica) was obtained from silica fume by carbonation process and surface modification. ${ }^{13,14)}$ The Si component in silica fume was leached by $\mathrm{NaOH}$ and transferred to $\mathrm{Na}_{2} \mathrm{SiO}_{3}$. Then $\mathrm{Na}_{2} \mathrm{SiO}_{3}$ solution was carbonated by $\mathrm{CO}_{2}$ to produce nano-silica.

$$
\begin{aligned}
& \mathrm{SiO}_{2}+2 \mathrm{OH}^{-}=\mathrm{SiO}_{3}{ }^{2-} \\
& \mathrm{SiO}_{3}{ }^{2-}+\mathrm{CO}_{2}=\mathrm{SiO}_{2} \downarrow+\mathrm{CO}_{3}{ }^{2-}
\end{aligned}
$$

About $80 \%$ of $\mathrm{Si}$ was recycled, and the purity of $\mathrm{SiO}_{2}$ produced was $95 \% .{ }^{14)}$ High silica microporous zeolite was synthesized by a hydrothermal method using silica fume as Si source, which exhibited high purity structure and a large surface area. ${ }^{15)}$ During the hydrothermal reaction, silica fume and $\mathrm{Al}$ source $\left(\mathrm{Al}_{2}\left(\mathrm{SO}_{4}\right)_{3} \cdot 18 \mathrm{H}_{2} \mathrm{O}\right)$ were gradually dissolved in $\mathrm{NaOH}$ to form monovalent monomers with negative charge $\left(\mathrm{Si}(\mathrm{OH})_{3} \mathrm{O}^{-}, \mathrm{Al}(\mathrm{OH})_{4}{ }^{-}\right) .^{15)}$

As a key factor for efficient utilization, the reactivity of Si component depended on the physicochemical structure of Si-O network. A better understanding of the structure and its effect on the reactivity behavior was beneficial to improve the utilization of silica fume. Generally, silica fume was non-crystalline material with disordered network structure based on silicon-oxygen tetrahedra [SiO4]., ${ }^{2,35}$ However, the microstructure of $\mathrm{Si}-\mathrm{O}$ network was still not analyzed in detail, which was highly relevant to the hydra- 
tion and alkali dissolution reactivity.

Therefore, in this study the chemical microstructure, especially $\mathrm{Si}-\mathrm{O}$ bonds and bridging oxygen structure, of $\mathrm{Si}-\mathrm{O}$ network in silica fume was characterized by XPS and FTIR. In order to estimate the type and the contribution of structural components, the spectra of $\mathrm{Si}$ and $\mathrm{O}$ were deconvoluted into elementary profiles. Then, the alkali dissolution reactivity of silica fume was examined using an isothermal kinetics method, and the kinetics parameters were determined based on the experimental data.

\section{Experimental Section}

\subsection{Materials}

The silica fume (SF) samples used in this study were provided by Ordos Metallurgy Group Corporation in Inner Mongolia, China. The samples were collected from a bagtype dust separator installed in an electric arc furnace gas cleaning system. The phase and chemical composition of silica fume were listed in Fig. S1 and Table S1, respectively. Silica fume was amorphous, exhibiting only a very broad scattering peak. The main chemical component (in oxide form) was $\mathrm{SiO}_{2}(96.97 \mathrm{wt} \%)$. The granulometric distribution analysis of silica fume was shown in Fig. S2. The mean particle size was about $4.5 \mu \mathrm{m}$. The BET surface area was about $23 \mathrm{~m}^{2} / \mathrm{g}$. $\mathrm{NaOH}$ with analytical grade (>97\%) was provided by provided by Beijing Chemical Reagents Company.

\subsection{Characterization}

\subsubsection{X-ray Photoelectron Spectroscopy}

X-ray photoelectron spectroscopy (XPS, AXISULTRADLD, Japan) was performed to determine the chemical states of $\mathrm{Si}$ and $\mathrm{O}$ present in silica fume. The Al K $\alpha$ (1 486.6 $\mathrm{eV}$ ) line was used for the X-ray source. The peak positions for binding energy of samples were corrected by considering the charging effect. A binding energy of $284.7 \mathrm{eV}$ was assumed for the $\mathrm{C} 1 \mathrm{~s}$ peak maximum in correcting for surface charging. PeakFit v4.12 software (SeaSolve Software Inc.) was used for fitting and deconvolution of $\mathrm{Si} 2 \mathrm{p}$ and $\mathrm{O}$ $1 \mathrm{~s}$ spectrum.

\subsubsection{FTIR Spectroscopy}

Fourier transform infrared spectrometer (FTIR, NICOIET-470, USA) was used to determine the chemical bonding of $\mathrm{Si}-\mathrm{Si}$ and $\mathrm{Si}-\mathrm{O}$. The FTIR spectra of the silica fume sample were recorded over the range of $4000-400$ $\mathrm{cm}^{-1}$ using the $\mathrm{KBr}$ pellet technique. The spectral resolution was $1 \mathrm{~cm}^{-1}$. Each measurement was taken at three different spots to eliminate the heterogeneity of the sample. ORIGIN 8.5 software was used for fitting and deconvolution of FTIR spectrum.

\subsection{Alkali Dissolution Reactivity and Kinetic}

The silica fume samples were dissolved by $\mathrm{NaOH}$ solution $(5-20 \mathrm{wt} \%)$ at a constant temperature $\left(50-80^{\circ} \mathrm{C}\right)$ in a $250 \mathrm{~mL}$ Jacketed PMMA reactor. The solid-liquid ratio and the stirring speed were $1: 10(\mathrm{~g} / \mathrm{mL})$ and $300 \mathrm{rpm}$, respectively. Then the samples of the solution were taken out by an adjustable volume pipette at a certain time interval, and each sampling volume was $0.25 \mathrm{~mL}$ (solution volume change was ignored). The sampling solution was transferred into a 25 $\mathrm{ml}$ volumetric flask and was diluted to $25 \mathrm{~mL}$ by deionized water. After the centrifugal separation, the concentration of $\mathrm{Si}$ of the upper clear liquid was determined by Inductively Coupled Plasma-Atomic Emission Spectrometry (ICP-AES, Perkine-Elmer OPTIMA 3000, USA). Finally, the conversion degree of $\mathrm{Si}(\eta)$ was calculated using the equation as followed:

$$
\eta=\frac{C_{\mathrm{Si}} \cdot V_{F} \cdot \frac{V_{R}}{V_{S}}}{m_{0} \omega} \times 100 \%
$$

where $C_{\mathrm{Si}}$ is the concentration of $\mathrm{Si}$ in the volumetric flask $(\mathrm{g} / \mathrm{L}) . V_{F}, V_{R}, V_{S}$ are the volume of the volumetric flask, the Jacketed PMMA reactor and the sampling solution (L), respectively. $m_{0}$ is the mass of silica fume $(\mathrm{g}) . \omega$ is the mass fraction of $\mathrm{Si}$ in the silica fume (wt\%).

\section{Results and Discussion}

\subsection{Chemical Structure of Si-O in Silica Fume}

\subsubsection{XPS Spectra}

The XPS analysis was used to identify the different states of $\mathrm{Si}$ and $\mathrm{O}$ on the surface of silica fume. The wide-scan spectrum of XPS analysis is shown in Fig. S3. The Si 2p spectrum ranging from 94 to $108 \mathrm{eV}$ is shown in Fig. 1. Asymmetry and broadening observed in Si $2 p$ spectra were because of the existence of different Si environments. XPS curve was subjected to peak fitting using PeakFit v4.12 software. The Si $2 p$ spectrum was deconvoluted into four elementary components (Gaussian type) at 103.8, 102.7, 101.4, and $100.5 \mathrm{eV}$ (Table 1). It is well known that some interme-

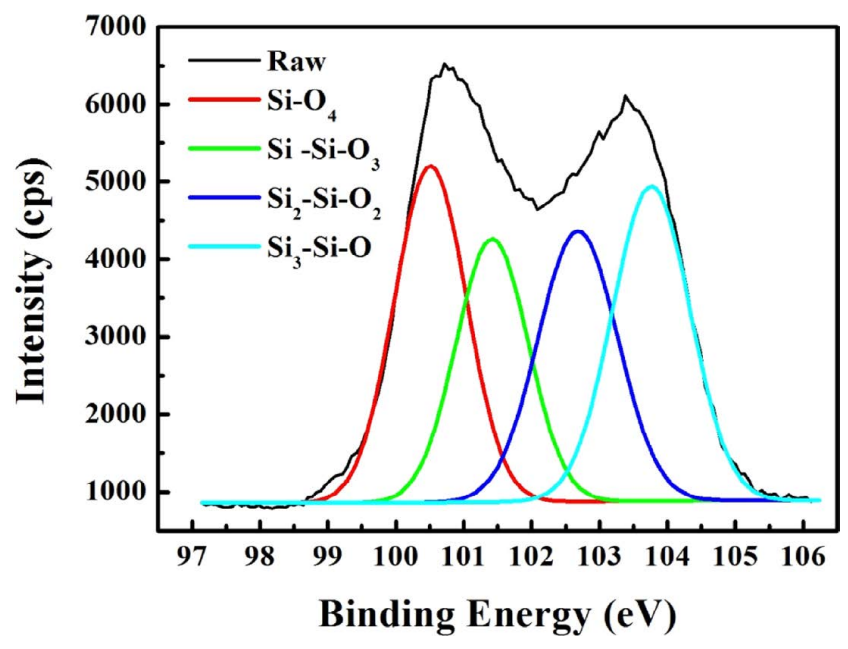

Fig. 1. XPS spectra of Si $2 p$ for silica fume. (Online version in color.)

Table 1. Fitting parameters obtained from XPS spectra of Si $2 p$ for silica fume.

\begin{tabular}{ccccc}
\hline $\begin{array}{c}\text { Binding energy } \\
(\mathrm{eV})\end{array}$ & Structure & $\begin{array}{c}\text { FWHM } \\
(\mathrm{eV})\end{array}$ & Peak area & $\begin{array}{c}\text { Contribution } \\
(\%)\end{array}$ \\
\hline 103.8 & $\mathrm{Si}-\mathrm{O}_{4}\left(\mathrm{Si}^{4+}\right)$ & 2.0 & 5811 & 27.4 \\
102.7 & $\mathrm{Si}-\mathrm{Si}-\mathrm{O}_{3}\left(\mathrm{Si}^{3+}\right)$ & 1.9 & 5113 & 24.1 \\
101.4 & $\mathrm{Si}_{2}-\mathrm{Si}-\mathrm{O}_{2}\left(\mathrm{Si}^{2+}\right)$ & 1.9 & 4506 & 21.3 \\
100.5 & $\mathrm{Si}_{3}-\mathrm{Si}-\mathrm{O}\left(\mathrm{Si}^{1+}\right)$ & 2.1 & 5753 & 27.2 \\
\hline
\end{tabular}


diate silicon oxide states exist at the $\mathrm{SiO}_{2} / \mathrm{Si}$ interface region during Si oxidation. These intermediate silicon oxide states have the same tetrahedral structure as $\mathrm{Si}-\mathrm{O}_{4}\left(\mathrm{Si}^{4+}\right.$ oxidation state, $\sim 103.5 \mathrm{eV}$ ). However, in amorphous silica oxide, $\mathrm{O}$ atom can be replaced partly by $\mathrm{Si}$ to form the tetrahedra: $\mathrm{Si}-\mathrm{Si}-\mathrm{O}_{3}\left(\mathrm{Si}^{3+}\right.$ oxidation state $), \mathrm{Si}_{2}-\mathrm{Si}-\mathrm{O}_{2}\left(\mathrm{Si}^{2+}\right.$ oxidation state) and $\mathrm{Si}_{3}-\mathrm{Si}-\mathrm{O}\left(\mathrm{Si}^{1+}\right.$ oxidation state) with binding energies of $100.7,101.5$ and $102.5 \mathrm{eV}$, respectively. ${ }^{16-18)}$ As the oxygen content of silicon oxide increased, the binding energy increased from 99.3 to $103.7 \mathrm{eV}$. Therefore, in this study the binding energies at 103.8, 102.7, 101.4, and $100.5 \mathrm{eV}$ were assigned to $\mathrm{Si}-\mathrm{O}_{4}, \mathrm{Si}-\mathrm{Si}-\mathrm{O}_{3}, \mathrm{Si}_{2}-\mathrm{Si}-\mathrm{O}_{2}$, and $\mathrm{Si}_{3}-\mathrm{Si}-\mathrm{O}$, respectively. The proportion of $\mathrm{Si}$ in different states was calculated by integrating the peak area. It was found that the contents of $\mathrm{Si}^{+4}, \mathrm{Si}^{+3}, \mathrm{Si}^{+2}$, and $\mathrm{Si}^{+1}$ were $27.4 \%, 24.1 \%, 21.3 \%$, and $27.2 \%$, respectively. Silica fume was generated by re-oxidation of $\mathrm{Si}$ and $\mathrm{SiO}$ vapor during Si production. ${ }^{2,3)}$ Because the vapor was rapidly cooled and condensed, the solidified oxide layer inhibited further oxidation of $\mathrm{Si}$ and $\mathrm{SiO}$ by $\mathrm{O}_{2}$. Some lower valence $\mathrm{Si}$ ( $\mathrm{Si}$ and $\mathrm{SiO})$ still existed in silica fume. Therefore, silica fume was the mixture of silica oxides with different oxidation states.

As shown in Fig. 2, the O $1 \mathrm{~s}$ spectra from 527 to $539 \mathrm{eV}$ were asymmetrical and broadening, suggesting that different chemical environments for oxygen existed in silica fume. The $\mathrm{O} 1 \mathrm{~s}$ spectrum was deconvoluted into three elementary components (Gaussian type) at 530.7, 532.9 and $534.8 \mathrm{eV}$ (Table 2). In the $\mathrm{SiO}_{2}$ structure, the bridging oxygen connected two $\mathrm{Si}$ atoms to form a more stable state $\mathrm{Si}-\mathrm{O}-\mathrm{Si}$ and thus had a lower binding energy than non-bridging oxygen. The energy difference between bridging and non-bridging oxygen was about $1.3 \mathrm{eV} .{ }^{19)}$ Therefore, the binding energies

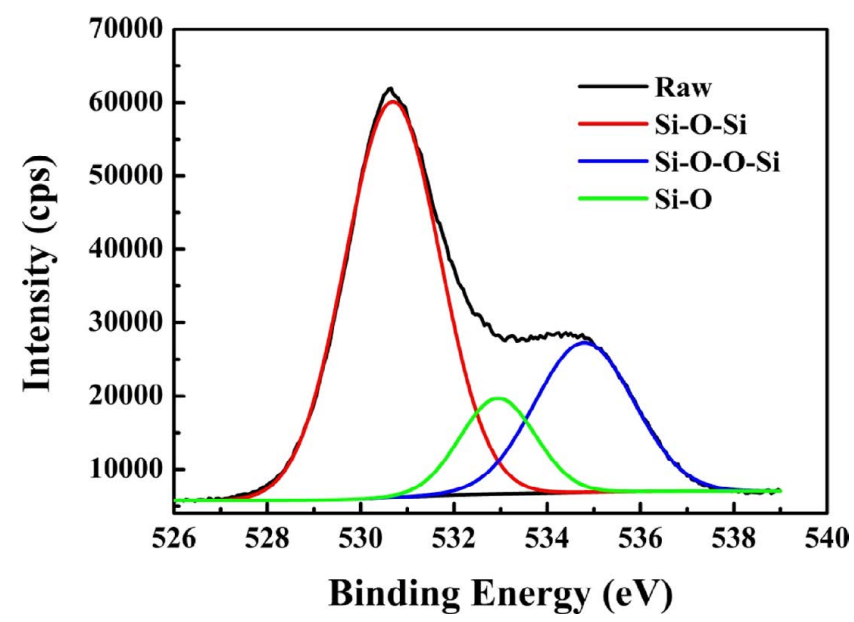

Fig. 2. XPS spectra of O $1 \mathrm{~s}$ for silica fume. (Online version in color.)

Table 2. Fitting parameters obtained from XPS spectra of O $1 \mathrm{~s}$ for silica fume.

\begin{tabular}{ccccc}
\hline $\begin{array}{c}\text { Binding energy } \\
(\mathrm{eV})\end{array}$ & Structure & $\begin{array}{c}\text { FWHM } \\
(\mathrm{eV})\end{array}$ & Peak area & $\begin{array}{c}\text { Contribution } \\
(\%)\end{array}$ \\
\hline 534.8 & $\begin{array}{c}\text { Si-O-O-Si } \\
\text { Peroxyl bridge }\end{array}$ & 2.5 & 54053 & 24.8 \\
532.9 & $\begin{array}{c}\text { Si-O } \\
\text { Non-bridge oxygen } \\
530.7\end{array}$ & 1.9 & 38406 & 17.6 \\
$\begin{array}{c}\text { Si-O-Si } \\
\text { Bridge oxygen }\end{array}$ & 2.4 & 125349 & 57.6 \\
\hline
\end{tabular}

at 530.7 and $532.9 \mathrm{eV}$ were assigned to the bridging oxygen and the non-bridging oxygen, respectively. The higher binding energy component at $534.8 \mathrm{eV}$ may be due to structural defects similar to the peroxyl bridge $\mathrm{Si}-\mathrm{O}-\mathrm{O}-\mathrm{Si} .{ }^{19)}$ The proportions of different states of oxygen were calculated by integrating the peak area, as shown in Table 2. It was found that the major elementary unit was the bridging oxygen, indicating high structural symmetry and bonding degree in the $\mathrm{Si}-\mathrm{O}$ network. The unsaturated $\mathrm{Si}-\mathrm{O}$ bonds (nonbridging oxygen) were considered as one of the causes for amorphous $\mathrm{SiO}_{2}{ }^{20)}$ However, the proportion of this structure was relatively small $(17.6 \%)$. Therefore, it was inferred that the non-crystallizing of silica fume was attributed to the atom arrangement in the $\mathrm{Si}-\mathrm{O}$ network.

\subsubsection{FTIR Spectra}

As shown in Fig. 3(a), the bands at $486 \mathrm{~cm}^{-1}$ and 805 $\mathrm{cm}^{-1}$ were assigned to the bending vibration of $\mathrm{O}-\mathrm{Si}-\mathrm{O}$ and symmetric stretching of $\mathrm{Si}-\mathrm{O}-\mathrm{Si}$, respectively. The strong band at $950-1360 \mathrm{~cm}^{-1}$ belonged to the asymmetric stretching modes of $\mathrm{Si}-\mathrm{O}$ bonds, which was deconvoluted into five elementary bands (Lorentzian type) as shown in Fig. 3(b) and Table 3. The $\mathrm{SiO}_{2}$ and silicate structure were composed of a series of elementary units of [SiO4] tetrahedron, $Q_{n}$, where $n$ is number of bridge oxygen around
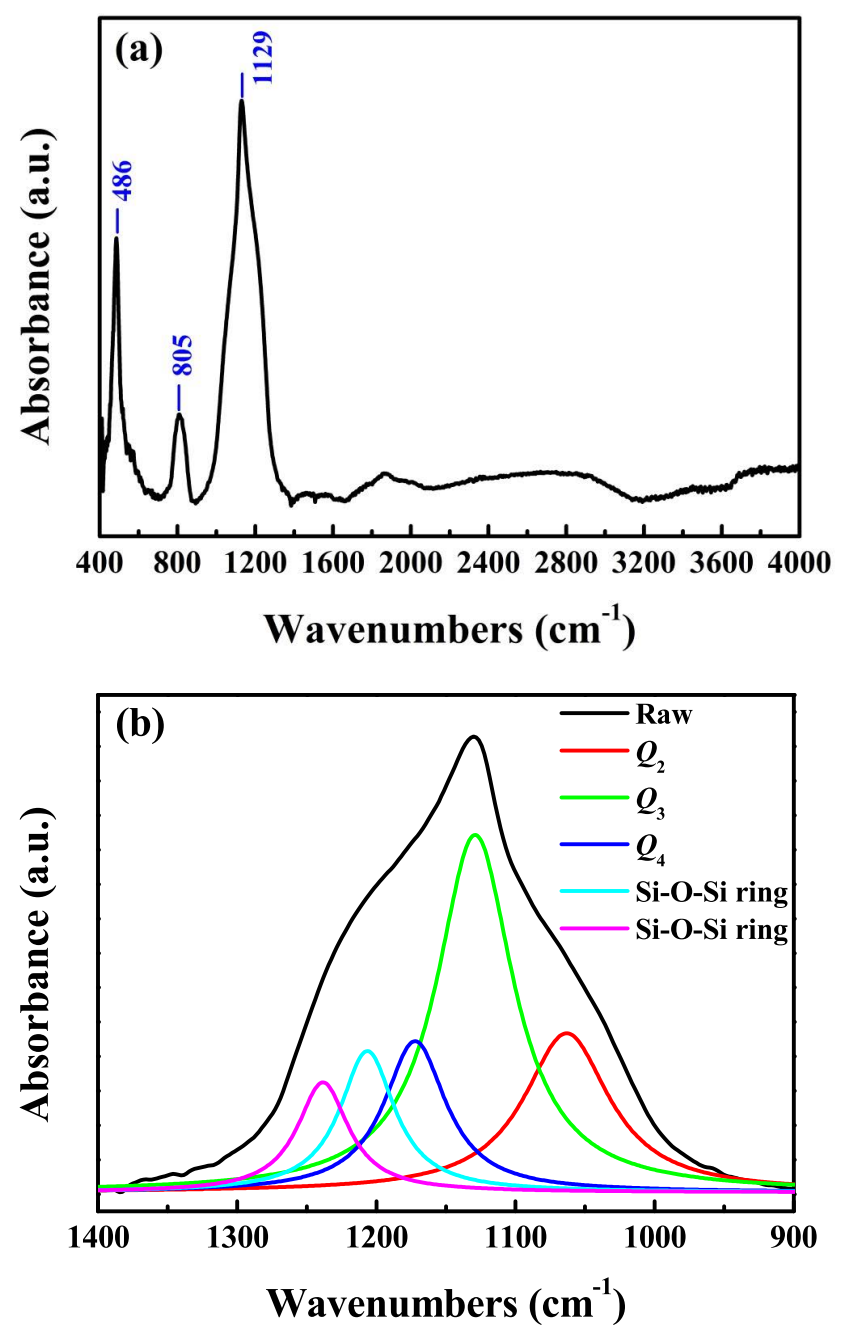

Fig. 3. FTIR spectra of silica fume: (a) $400-4000 \mathrm{~cm}^{-1}$ region; (b) Deconvolution of 900-1 $400 \mathrm{~cm}^{-1}$ region. (Online version in color.) 
Table 3. Fitting parameters obtained from FTIR spectra $\left(900-1400 \mathrm{~cm}^{-1}\right)$ of silica fume.

\begin{tabular}{cccccc}
\hline $\begin{array}{c}\text { Band } \\
\text { position } \\
\left(\mathrm{cm}^{-1}\right)\end{array}$ & Structure & $\begin{array}{c}\mathrm{Si}-\mathrm{O}-\mathrm{Si} \\
\text { angle } \\
\left({ }^{\circ}\right)\end{array}$ & $\begin{array}{c}\mathrm{FWHM} \\
\left(\mathrm{cm}^{-1}\right)\end{array}$ & $\begin{array}{c}\text { Peak } \\
\text { area }\end{array}$ & $\begin{array}{c}\text { Contribution } \\
(\%)\end{array}$ \\
\hline 1063.3 & $\mathrm{Si}_{2} \mathrm{O}_{6}{ }^{6-}\left(Q_{2}\right)$ & 134.3 & 74.8 & 1640.6 & 20.9 \\
1129.0 & $\mathrm{Si}_{2} \mathrm{O}_{5}{ }^{4-}\left(Q_{3}\right)$ & 164.7 & 66.8 & 3366.9 & 42.8 \\
1172.2 & $\mathrm{SiO}_{2}\left(Q_{4}\right)$ & 115.8 & 54.1 & 1172.7 & 14.9 \\
1206.5 & $\mathrm{Si}-\mathrm{O}-\mathrm{Si}$ ring & 125.8 & 47.8 & 975.0 & 12.4 \\
1238.4 & $\mathrm{Si}-\mathrm{O}-\mathrm{Si}$ ring & 136.9 & 44.8 & 711.4 & 9.0 \\
\hline
\end{tabular}

$[\mathrm{SiO} 4]^{20)}$ The elementary unit was formed by the polymerization of [SiO4] tetrahedron. The FTIR vibrational modes of silica fume were associated with the structural configurations of $\mathrm{Si}-\mathrm{O}$ bonds. As the polymerization of [ $\mathrm{SiO} 4]$ tetrahedron increased, the number of bridge oxygen increased. The absorption bands at $1063.3,1129.0$ and $1172.2 \mathrm{~cm}^{-1}$ were associated to the asymmetric stretching modes of the $\mathrm{Si}-\mathrm{O}$ bonds of the $Q_{2}, Q_{3}$ and $Q_{4}$ units, respectively. ${ }^{18)}$ These bands shifted to higher wavenumbers because of the variation of $\mathrm{Si}-\mathrm{O}$ bond angles. ${ }^{21,22)}$ The proportions of the $Q_{n}$ units were calculated by integrating the peak area. As shown in Table 3, the major elementary unit was $Q_{3}$, indicating a high degree of polymerization of [SO4]. Based on the distribution of $Q_{2}, Q_{3}$ and $Q_{4}$, the content of non-bridge oxygen was calculated to be $21.4 \%$, which was in accord with the result of XPS.

The bands at $>1200 \mathrm{~cm}^{-1}$ were assigned to the local vibration absorption of $\mathrm{Si}-\mathrm{O}$ due to the impurity oxygen. ${ }^{21-23)}$ In this structure, $\mathrm{O}$ atoms (bridge oxygen) were inserted in the lattice of $\mathrm{Si}$ as a bridge to connect the neighboring $\mathrm{Si}$ atoms, leading to the formation of $\mathrm{Si}-\mathrm{O}-\mathrm{Si}$ interconnecting rings in the $\mathrm{Si}-\mathrm{O}$ network. The $\mathrm{Si}-\mathrm{O}-\mathrm{Si}$ rings also included the peroxyl bridge structure as mentioned in section 3.1.1. As the number of bridge oxygen increased, the bands of $\mathrm{Si}-\mathrm{O}$ shifted to higher wavenumbers due to the stronger $\mathrm{Si}-\mathrm{O}$ bonds in the $\mathrm{Si}-\mathrm{O}-\mathrm{Si}$ rings. According to the positions of the maximum of elementary components $(w)$ in FTIR spectrum, the mean values of $\mathrm{Si}-\mathrm{O}-\mathrm{Si}$ bond angles $(\theta)$ can be calculated: ${ }^{21,22)}$

When $1010 \mathrm{~cm}^{-1}<w<1140 \mathrm{~cm}^{-1}$

$$
w=(2 \pi c)^{-1}\left[\frac{2}{m}\left(\alpha \sin ^{2} \frac{\theta}{2}+\beta \cos ^{2} \frac{\theta}{2}\right)\right]^{\frac{1}{2}} .
$$

When $1140 \mathrm{~cm}^{-1}<w<1300 \mathrm{~cm}^{-1}$

$$
w=(2 \pi c)^{-1}\left[\frac{2}{m}\left(\alpha \sin ^{2} \frac{\theta}{2}+\beta \cos ^{2} \frac{\theta}{2}+\gamma\right)\right]^{\frac{1}{2}} \ldots \ldots . .
$$

where $m$ is the mass of oxygen atom $\left(2.657 \times 10^{-26} \mathrm{~kg}\right) ; \alpha$ and $\beta$ are the central and non-central force constants (610 and $100 \mathrm{~N} / \mathrm{m}$, respectively $\left.{ }^{21)}\right) ; \gamma$ is a constant $(181.82 \mathrm{~N} /$ $\left.\mathrm{m}^{22)}\right) ; c$ is the velocity of light $\left(2.997 \times 10^{8} \mathrm{~m} / \mathrm{s}\right)$. As listed in Table 3, the distribution of $\mathrm{Si}-\mathrm{O}-\mathrm{Si}$ angles in the structural units of silica fume was rather wide $\left(115.8^{\circ}<\theta<164.7^{\circ}\right)$ due to mixing of the different types of elementary units. It indicated that the structural ordering of $\mathrm{Si}-\mathrm{O}$ network decreased. ${ }^{21,22)}$ The $\mathrm{Si}-\mathrm{O}-\mathrm{Si}$ bond angle of the $Q_{4}$ unit was

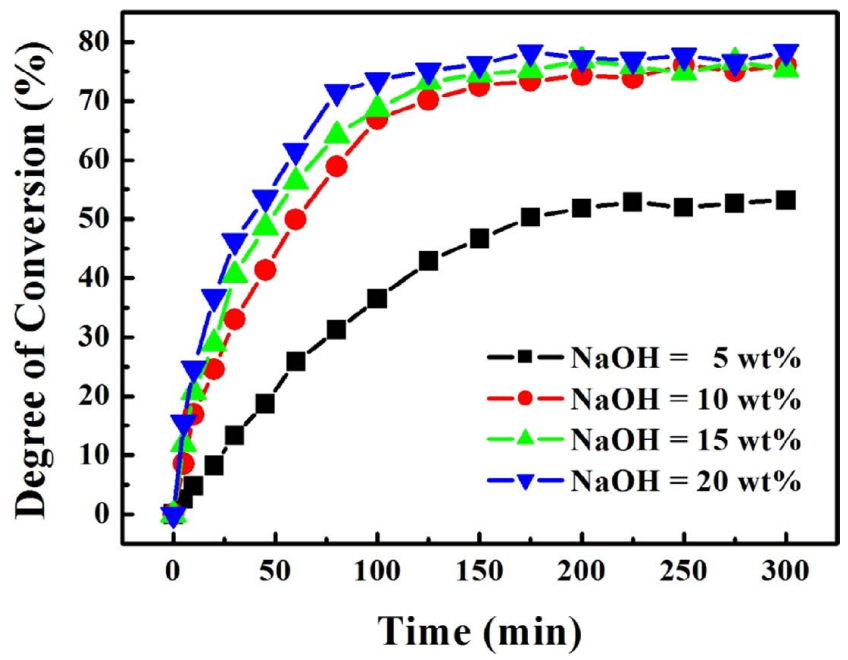

Fig. 4. The effect of $\mathrm{NaOH}$ concentration on the conversion degree of $\mathrm{Si}\left(70^{\circ} \mathrm{C}\right)$. (Online version in color.)

$115.8^{\circ}$, which was close to the theoretical value of $109.5^{\circ}$. Therefore, the $Q_{4}$ unit was the orderly [SiO4] tetrahedron in $\mathrm{SiO}_{2}$ crystalline structure. However, the proportion of this structure was relatively small (only $14.91 \%$ ). As a result, the structure of silica fume was predominantly amorphous and disordered.

\subsection{Alkali Dissolution Reactivity of Silica Fume}

3.2.1. Effects of $\mathrm{NaOH}$ Concentration

The effect of $\mathrm{NaOH}$ concentration on the conversion degree of $\mathrm{Si}$ was investigated when the reaction temperature was $70^{\circ} \mathrm{C}$. The conversion degree of $\mathrm{Si}$ increased with increasing the $\mathrm{NaOH}$ concentration (Fig. 4). When the $\mathrm{NaOH}$ concentration was $5 \mathrm{wt} \%$, the conversion degree of $\mathrm{Si}$ was lower (only $50 \%$ ). When the $\mathrm{NaOH}$ concentration was increased from 5 to $10 \mathrm{wt} \%$, the conversion degree of $\mathrm{Si}$ increased notably up to about $70 \%$. However, when the $\mathrm{NaOH}$ concentration was higher than $10 \mathrm{wt} \%$, the conversion degree of Si was almost unchanged and reached about $70-75 \%$. As the $\mathrm{NaOH}$ concentration increased, the activity of $\mathrm{OH}^{-}$increased. The interaction between $\mathrm{OH}^{-}$and amorphous $\mathrm{SiO}_{2}$ was stronger, and thus it was easier for $\mathrm{OH}^{-}$to be absorbed on the surface of $\mathrm{SiO}_{2}$. As a result, the dissolution of amorphous $\mathrm{SiO}_{2}$ was enhanced. However, when the $\mathrm{NaOH}$ concentration was higher than $10 \mathrm{wt} \%$, the ionic strength $(I)$ was increased significantly, and the activity coefficient $(\gamma)$ was decreased. ${ }^{24)}$ Thus, the increase of the $\mathrm{OH}^{-}$activity was small. In addition, the viscosity of $\mathrm{NaOH}$ solution also increased, limiting the diffusion of $\mathrm{OH}^{-}$. Therefore, the conversion degree of $\mathrm{Si}$ was increased slowly.

\subsubsection{Effects of Reaction Temperature}

The effect of reaction temperature on the conversion degree of $\mathrm{Si}$ was investigated from 50 to $80^{\circ} \mathrm{C}$. The $\mathrm{NaOH}$ concentration was $10 \mathrm{wt} \%$. At the same reaction time, the conversion degree of $\mathrm{Si}$ increased with increasing the temperature especially at the early stage (less than $400 \mathrm{~min}$ ). At the reaction time of $200 \mathrm{~min}$, for example, the conversion degree of $\mathrm{Si}$ increased notably from about $46.3 \%$ at $50^{\circ} \mathrm{C}$ up to $74.4 \%$ at $70^{\circ} \mathrm{C}$ (Fig. 5). But when the temperature was $>70^{\circ} \mathrm{C}$, the conversion degree of $\mathrm{Si}$ increased only from 


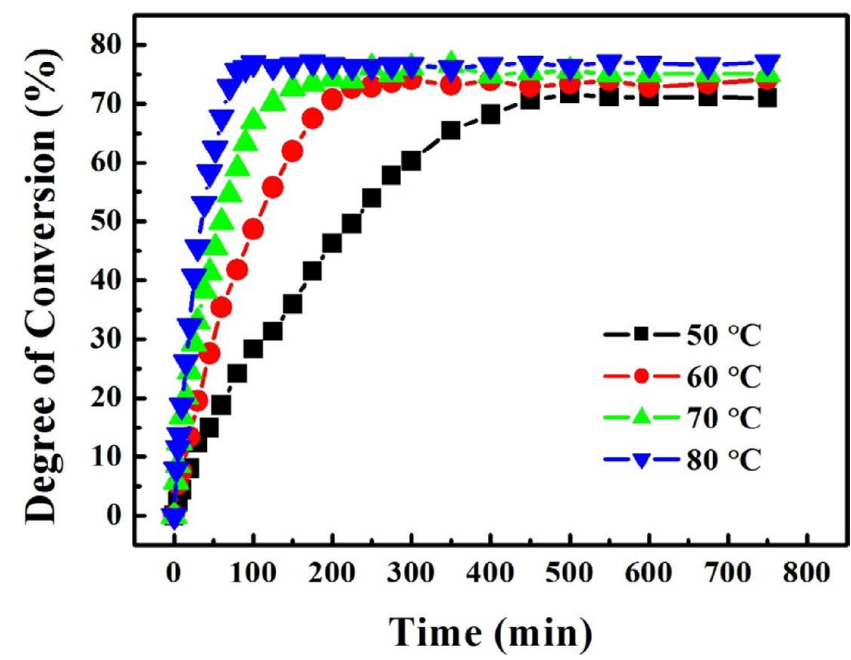

Fig. 5. The effect of reaction temperature on the conversion degree of $\mathrm{Si}(\mathrm{NaOH}=10 \mathrm{wt} \%)$. (Online version in color.)

$74.4 \%$ at $70^{\circ} \mathrm{C}$ to $76.6 \%$ at $80^{\circ} \mathrm{C}$, and the increasing speed declined significantly. The results indicated that increasing temperature enhanced the dissolution of silica fume in $\mathrm{NaOH}$ solution. The rise in temperature of the leaching system increased the mobility of ions and thereby enhancing the interaction between ions of solid and liquid phase. Thus, when the temperature was up to $70^{\circ} \mathrm{C}$, the conversion degree of $\mathrm{Si}$ increased notably because the reaction rate and diffusion was enhanced. At temperatures $>70^{\circ} \mathrm{C}$, the reagents had been almost fully activated, and thus the changes of reaction rate and the Si conversion degree were not remarkable.

\subsubsection{Kinetics Models}

In order to deduce the reaction mechanism and determine the kinetics parameters, the most probable kinetics model is evaluated corresponding to the kinetics data. It is usual to postulate a kinetics model and the rate-determining step for reaction based on the experimental observations. Therefore, this paper tried to present a kinetics model for the alkali dissolution of silica fume.

Kinetics analysis of thermally stimulated reactions is traditionally expected to produce an adequate kinetics description of the process in terms of the reaction model and of the Arrhenius parameters using a solid- solid kinetics equation: $:^{25,26)}$

$$
\frac{\mathrm{d} X}{\mathrm{~d} t}=k(T) f(X)
$$

where $X$ is the conversion degree of reaction, $t$ is the reaction time, $T$ is the reaction temperature, $f(X)$ is the reaction model, $k(T)$ is the kinetics rate constant, which is given as:

$$
k(T)=k_{0} \exp \left(\frac{-E}{R T}\right)
$$

By taking the logarithm and rearranging it, one can obtain:

$$
\ln k(T)=\ln k_{0}-\frac{E}{R T}
$$

where $R$ is the gas constant $\left(8.314 \mathrm{~J} \cdot \mathrm{mol}^{-1} \cdot \mathrm{K}^{-1}\right), k_{0}$ is the pre-exponential factor, $E$ is the apparent activation energy. For reaction kinetics under isothermal conditions, Eq. (3) can be analytically integrated to yield:

$$
G(X)=\int_{0}^{X} \frac{\mathrm{d} X}{f(X)}=k(T) t
$$

where $G(X)$ is the integral form of the reaction model. By combining Eqs. (3)-(5), the kinetics rate constant $[k(T)]$ can be obtained from the slope of linear regression of $G(X)$ and $t$ at different temperatures using a reasonable kinetics model $[G(X)]$. Then By plotting $\ln k(T)$ versus the reciprocal of reaction temperature $(1 / T)$ according to Eq. (5), the apparent activation energy and pre-exponential factor can be obtained by the slope and the intercept of linear regression, respectively.

\subsubsection{Model Evaluation}

In order to evaluate the kinetics model and the ratecontrolled mechanism, the kinetics data ( $X$ versus $t$ ) were needed. Thus, the effect of the reaction time on the conversion degree of $\mathrm{Si}$ was examined from $50^{\circ} \mathrm{C}$ to $80^{\circ} \mathrm{C}$ $(\mathrm{NaOH}=10 \mathrm{wt} \%)$ (Fig. 5). The results indicated that the conversion degree of $\mathrm{Si}$ increased with the reaction time. At $50-60^{\circ} \mathrm{C}$, the conversion degree of $\mathrm{Si}$ increased rapidly from 0 to $300 \mathrm{~min}$ and reached a maximum at about $350 \mathrm{~min}$. At $70-80^{\circ} \mathrm{C}$, the conversion degree of $\mathrm{Si}$ increased rapidly from 0 to $100 \mathrm{~min}$ and reached a maximum at about 120 min. In the process of alkali dissolution, the following three steps occurred in succession: (1) Diffusion of $\mathrm{OH}^{-}$from the $\mathrm{NaOH}$ solution through the liquid film to the surface of silica fume; (2) Reaction on the surface between $\mathrm{OH}^{-}$and silica fume; (3) Diffusion of reaction products $\left(\mathrm{SiO}_{3}{ }^{2-}\right)$ from the surface of the solid through the liquid film back into the $\mathrm{NaOH}$ solution. Because the reaction product was the soluble $\mathrm{SiO}_{3}{ }^{2-}$, the reacting particle shrank during reaction and finally disappeared, and the size of particles was changing with time. There was no solid product layer formed, and thus internal diffusion in the solid particles did not contribute any reaction resistance. Therefore, the alkali dissolution reaction of silica fume suited to a shrinking-core model for unchanging size. When the reaction was controlled by chemical reaction between $\mathrm{OH}^{-}$and silica fume, the dissolution process of mono-sized particles was predicted based on the shrinking core model. The integral form of the reaction model $[G(X)]$ was expressed as: ${ }^{27)}$

$$
G(X)=1-(1-X)^{\frac{1}{3}}
$$

Substituting Eq. (7) into Eq. (6), the model equation was expressed as:

$$
1-(1-X)^{\frac{1}{3}}=k(T) t
$$

where $X$ is the conversion degree.

Due to the very small size of silica fume (average diameter $<100 \mathrm{~nm}$ ) according to SEM observation result (Fig. S4), the mass transfer coefficient of the liquid film was in the Stokes law regime and was inversely proportional to the particle size. ${ }^{27)}$ Therefore, when the reaction was controlled by the diffusion of $\mathrm{OH}^{-}$through the liquid film, the integral form of the reaction model $[G(X)]$ was expressed as: ${ }^{27)}$ 


$$
G(X)=1-(1-X)^{\frac{2}{3}}
$$

Substituting Eq. (9) into Eq. (6), the model equation was expressed as:

$$
1-(1-X)^{\frac{2}{3}}=k(T) t
$$

According to the kinetics data in Fig. 5, it was found that none of the one-step process models $\left(1-(1-X)^{1 / 3}\right.$ and $\left.1-(1-X)^{2 / 3}\right)$ fitted the data. The plot of $1-(1-X)^{2 / 3}$ versus $t$ showed an excellent linear relation when the conversion degree was $X<0.35$. However, the regression of $1-(1-X)^{1 / 3}$ versus $t$ was straight-line when the conversion degree was $0.35<X<0.6$. Therefore, it was inferred that the process of alkali dissolution was multi-stepped. The rate controlling mechanisms at $X<0.35$ and $0.35<X<0.6$ were diffusion through the liquid film and chemical reaction, respectively. In order to obtain the kinetics parameters, substituting the data of the conversion degree of Si into Eqs. (7) and (9), the values of $1-(1-X)^{2 / 3}$ and $1-(1-X)^{1 / 3}$ can be calculated. According to Eqs. (8) and (10), the values of kinetics rate constant, $k(T)$, were determined from the slope obtained a regression line by plotting $1-(1-X)^{2 / 3}$ and $1-(1-X)^{1 / 3}$ versus $t$ at different temperatures as shown in Figs. 6(a) and 7(a). The values of $\ln k(T)$ also were calculated by taking
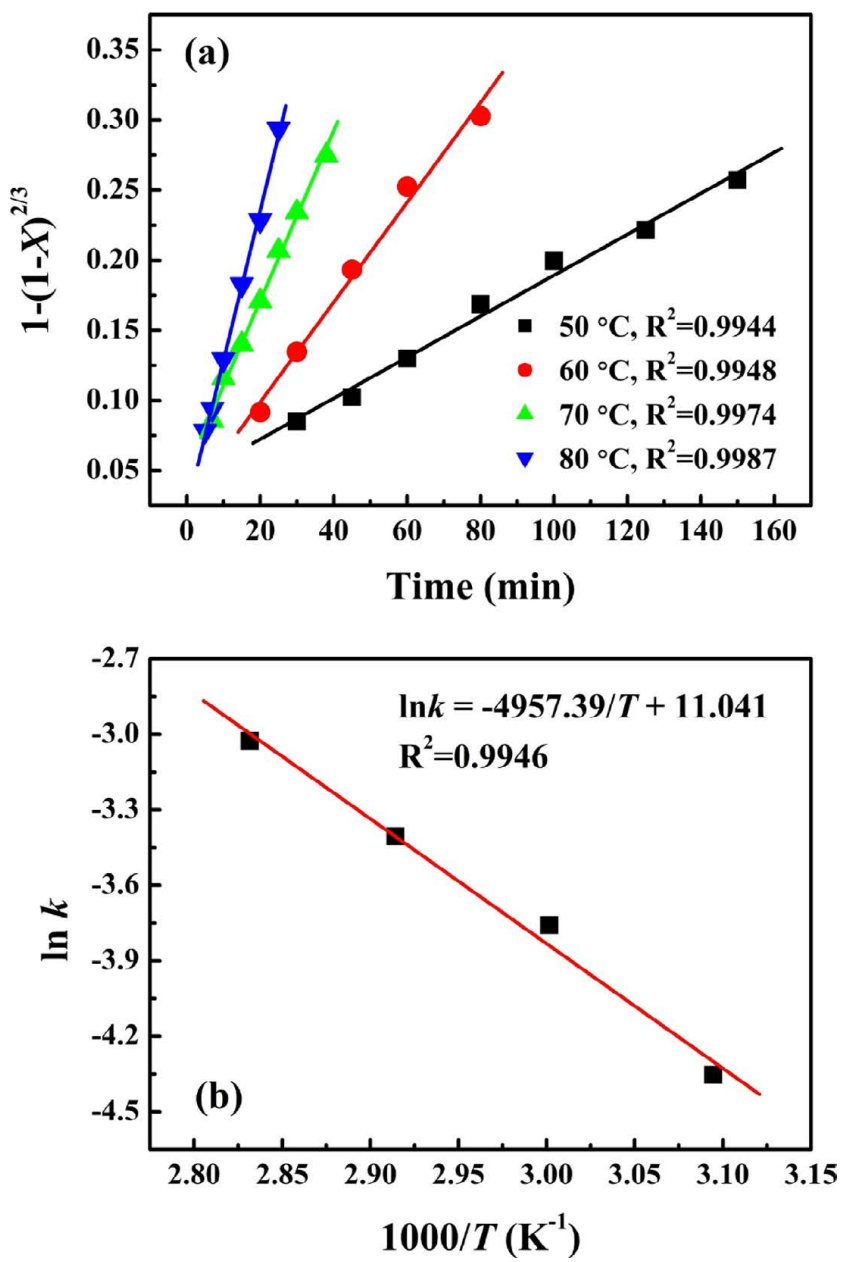

Fig. 6. Kinetics analysis of alkali dissolution $(X<0.35)$ : (a) The plot of $1-(1-X)^{2 / 3}$ against reaction time at different temperature; (b) The plot of $\ln k(T)$ and $1 / T$. (Online version in color.) the logarithm of $k(T)$. Subsequently, the apparent activation energy and pre-exponential factor were obtained from the slope and intercept by linear regression of $\ln k(T)$ with the reciprocal of reaction temperature $(1 / T)$ in the Arrhenius equation (Eq. (5)).

According to the data from Fig. 5, the plots of 1$(1-X)^{2 / 3}$ and $1-(1-X)^{1 / 3}$ with $t$ at different temperatures are depicted in Figs. 6(a) and 7(a), respectively. The values of $k(T)$ were obtained from the slope of a linear regression between $G(X)$ and $t$. Regression analysis showed that the correlation coefficients for all the fittings were $>0.99$, which supported a good linear relation between $G(X)$ and $t$. That is, the staged model (Eqs. (8) and (10)) fitted the kinetics data. Therefore, it was indicated that our assumption about the kinetics model was reasonable. Then the value of $-E / R$ was obtained from the slope of a linear regression between $\ln k(T)$ and $1 / T$. The apparent activation energies $(E)$ at $X<0.35$ and at $0.35<X<0.6$ were calculated as $42.22 \pm 3.03$ and $78.06 \pm 4.27 \mathrm{~kJ} / \mathrm{mol}$, respectively (Figs. 6(b) and 7(b)).

In the process of alkali dissolution, $\mathrm{OH}^{-}$groups adsorbed the surface $\mathrm{Si}$ atoms, increasing its electronic density and weakening the $\mathrm{Si}-\mathrm{O}$ bonds. ${ }^{28-31)}$ And the depolymerization of $\mathrm{Si}-\mathrm{O}-\mathrm{Si}$ bonds increased the reactivity of the neighboring $\mathrm{Si}$ atom due to the creation of surface $\mathrm{Si}-\mathrm{OH}$ groups. ${ }^{28)} \mathrm{In}$ the early stage of the reaction, the increase of dissolution rate was attributed to the reactive high energy sites on the
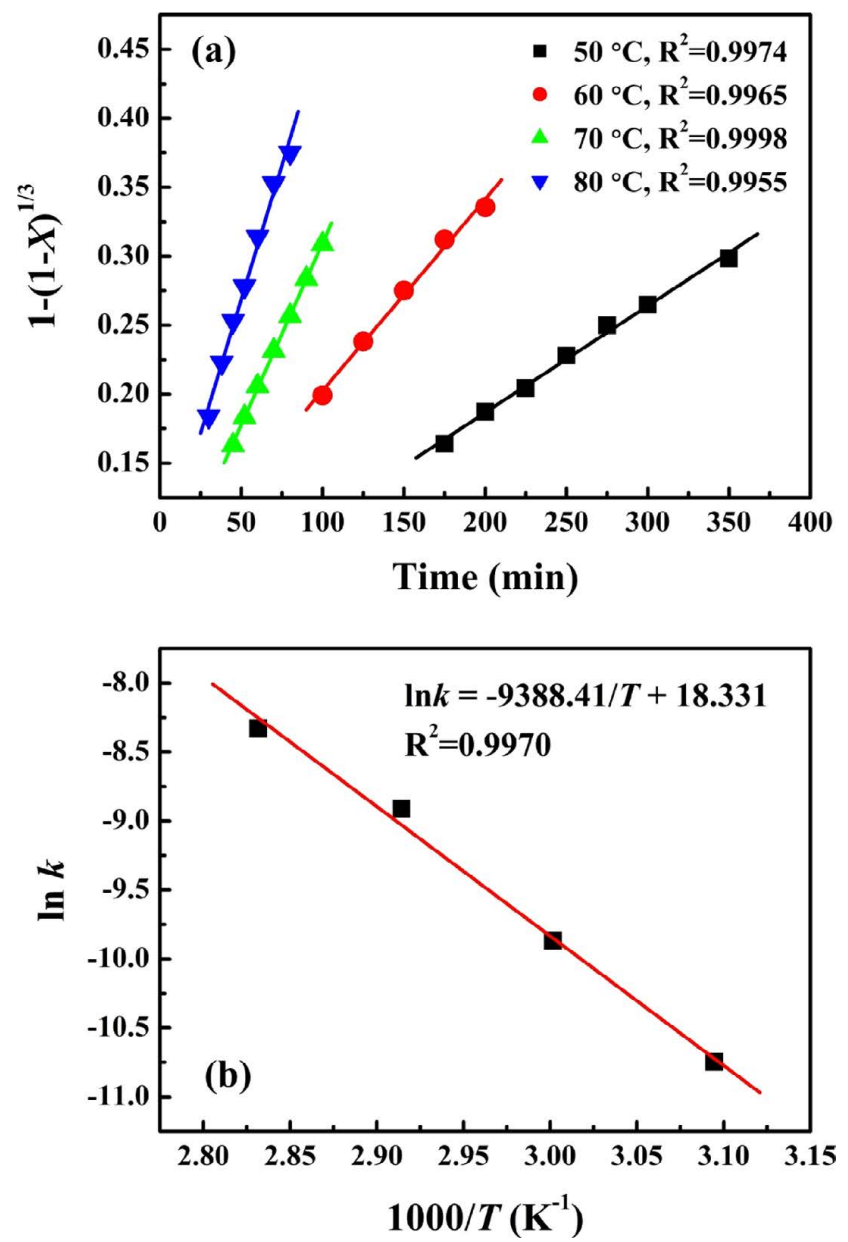

Fig. 7. Kinetics analysis of alkali dissolution $(0.35<X<0.6)$ : (a) The plot of $1-(1-X)^{1 / 3}$ against reaction time at different temperature; (b) The plot of $\ln k(T)$ and $1 / T$. (Online version in color.) 
surface of silica fume. These high energy sites were associated with the distorted $\mathrm{Si}-\mathrm{O}-\mathrm{Si}$ bonds and low-coordinated Si atoms. ${ }^{28,31)}$ As discussed in Section 3.1, the proportion of the unsaturated $\mathrm{Si}-\mathrm{O}$ bonds $\left(Q_{2}, Q_{3}\right.$ units and the peroxyl bridge structure) accounted for $42.45 \%$. The bond angles of $Q_{2}\left(134.3^{\circ}\right)$ and $Q_{3}\left(164.7^{\circ}\right)$ were deviated largely from the stable value of tetrahedron $\left(109.5^{\circ}\right)$. Si-O-Si bonds were distorted, and thus the strength of $\mathrm{Si}-\mathrm{O}$ was weakened. Besides, non-bridging oxygen, especially the peroxyl bridge structure ( $\mathrm{Si}-\mathrm{O}-\mathrm{O}-\mathrm{Si}$ ), also resulted in a loose structure of the $\mathrm{Si}-\mathrm{O}$ network to disintegrate. Therefore, $\mathrm{Si}-\mathrm{O}$ bonds of non-crystalline $\mathrm{SiO}_{2}$ in silica fume were easier to be broken by $\mathrm{OH}^{-}$. It was reasonable to consider that the dissolution rate at $X<0.35$ was much greater than the $\mathrm{OH}^{-}$diffusion rate in liquid film. However, in the later stage of the reaction $(0.35<X<0.6)$, most of amorphous $\mathrm{SiO}_{2}$ with distorted $\mathrm{Si}-\mathrm{O}$ bonds was dissolved. The residue was mainly crystalline $\mathrm{SiO}_{2}$ with the orderly [SiO4] tetrahedron unit $\left(Q_{4}\right)$. The dissolution rate was much slower than that in the early stage of the reaction. Consequently, the rate controlling step was the chemical reaction between $\mathrm{OH}^{-}$and $\mathrm{SiO}_{2}$. A similar activation energy value $(82 \pm 6 \mathrm{~kJ} / \mathrm{mol})$ was reported for the dissolution of $\mathrm{SiO}_{2}$ aerogel in $\mathrm{NaOH}$ at $15-56^{\circ} \mathrm{C}$. ${ }^{28)}$ It also suggested that the assumption of the rate-controlling step was reasonable. Finally, the alkali dissolution kinetics model of silica fume was established. The kinetics equation was expressed as:

$$
\begin{array}{ll}
1-(1-X)^{\frac{2}{3}}=62380 \exp \left(-\frac{4957.39}{T}\right) t \quad(X<0.35) \\
1-(1-X)^{\frac{1}{3}}=91422 \exp \left(-\frac{9388.41}{T}\right) t \quad(0.35<X<0.6)
\end{array}
$$

\section{Conclusions}

In this paper, the structural characterization by several analytical techniques was carried out in order to analyze the chemical structure of $\mathrm{Si}-\mathrm{O}$ bonds in silica fume for developing the recycling methods. XPS analysis showed the presence of $\mathrm{Si}^{+4}, \mathrm{Si}^{+3}, \mathrm{Si}^{+2}$, and $\mathrm{Si}^{+1}$. Silica fume was a mixture of silicon oxides with multiple valence states. The structures of bridging, non-bridging and the peroxyl bridge ( $\mathrm{Si}-\mathrm{O}-\mathrm{O}-$ $\mathrm{Si}$ ) oxygen existed in the $\mathrm{Si}-\mathrm{O}$ bonding. The FTIR spectra showed that the elementary units of $Q_{2}, Q_{3}, Q_{4}$ and $\mathrm{Si}-\mathrm{O}-\mathrm{Si}$ rings constituted the $\mathrm{Si}-\mathrm{O}$ network in silica fume. The distribution of $\mathrm{Si}-\mathrm{O}-\mathrm{Si}$ angles in the structural units was wide $\left(115.8^{\circ}<\theta<164.7^{\circ}\right)$. The proportions of the non-bridging oxygen and the ordered [SO4] structure were small. Therefore, the non-crystallizing of silica fume was attributed to the $\mathrm{Si}-\mathrm{O}-\mathrm{Si}$ atom arrangement (bond angles).

For alkali dissolution reactivity, the kinetics model was divided into two stages. When the conversion degree was $<0.35$, the rate controlling step was the diffusion of $\mathrm{OH}^{-}$ through the liquid film, and the apparent activation energy was $42.22 \pm 3.03 \mathrm{~kJ} / \mathrm{mol}$. When the conversion degree was $0.35<X<0.6$, the rate controlling step was the chemical reaction of $\mathrm{OH}^{-}$with $\mathrm{Si}-\mathrm{O}$, and the apparent activation energy was $78.06 \pm 4.27 \mathrm{~kJ} / \mathrm{mol}$. The obtained data provided useful information as an important base for the further studies of utilizing silica fume.

\section{Acknowledgements}

This work was financially supported by National High Technology Research and Development Program of China (No. 2012AA06A118) and Fundamental Research Funds for the Central Universities (No. FRF-TP-17-040A2).

\section{Supporting Information}

Details about XRD, XRF, XPS data and particle size distribution of the silica fume sample are given in Figs. S1, S2, S3, S4 and Table S1 in Supporting Information.

This materials is available on the website at https://doi. org/10.2355/isijinternational.ISIJINT-2018-516.

\section{REFERENCES}

1) O. Wijk and V. Brabie: ISIJ Int., 36 (1996), 132.

2) Y. R. Mao, P. Shen, Q. H. Sun and H. Qu: Recycl. Res., 6 (2005), 34.

3) F. R. Zhai: China Resour. Compr. Util., 8 (2003), 31.

4) J. Bensted and P. Barnes: Structure and Performance of Cements, 2nd ed., Spon Press, London/New York, (2001), 125.

5) M. I. Khan and R. Siddique: Resour. Conserv. Recycl., 57 (2011), 30.

6) S. A. Barbhuiya, J. K. Gbagbo, M. I. Russell and P. A. M. Basheer: Constr. Build. Mater., 23 (2009), 3233.

7) T. Nochaiya, W. Wongkeo and A. Chaipanich: Fuel, 89 (2010), 768.

8) V. Lilkov, I. Rostovsky, O. Petrov, Y. Tzvetanova and P. Savov: Constr. Build. Mater., 60 (2014), 48.

9) F. N. Okoye, J. Durgaprasad and N. B. Singh: Ceram. Int., 42 (2016), 3000 .

10) K. Somna, C. Jaturapitakkul, P. Kajitvichyanukul and P. Chindaprasirt: Fuel, 90 (2011), 2118

11) J. Liu and D. Wang: Powder Technol., 320 (2017), 230.

12) J. Zhang, Z. Guo, X. Zhi and H. Tang: Colloids Surf. A, 418 (2013), 174.

13) X. Zhi and Z. Guo: Appl. Mech. Mater., 423-426 (2013), 554

14) V. Jafari, A. Allahverdi and M. Vafaei: Adv. Powder Technol., 25 (2014), 1571.

15) Y. Wang, J. Chen, X. Lei, Y. Ren and J. Wu: Adv. Powder Technol., 29 (2018), 1112

16) S. I. Raider and R. Flitsch: J. Electrochem. Soc., 123 (1976), 1754.

17) R. Alfonsetti, G. De Simone, L. Lozzi, M. Passacantando, P. Picozzi and S. Santucci: Surf. Interface Anal., 22 (1994), 89.

18) T. P. Nguyen and S. Lefrant: J. Phys. Condens. Matter, 1 (1989), 5197.

19) H. Li, S. Dimitrijev, D. Sweatman, H. B. Harrison and P. Tanner: $J$. Appl. Phys., 86 (1999), 4316.

20) A. Aronne, S. Esposito and P. Pernice: Mater. Chem. Phys., 51 (1997), 163.

21) I. P. Lisovskii, V. G. Litovchenko, V. G. Lozinskii and G. I. Steblovskii: Thin Solid Films, 213 (1992), 164.

22) I. P. Lisovskii, V. G. Litovchenko, V. B. Lozinskii, S. I. Frolov, H Flietner, W. Fussel and E. G. Schmidt: J. Non-Cryst. Solids, 187 (1995), 91

23) S. Chen, S. Xie and G. He: Semicond. Optoelectron., 25 (2004), 372.

24) R. J. Silbey, R. A. Alberty and M. G. Bawendi: Physical Chemistry, 4th ed., John Wiley \& Sons, New York, (2004), 229.

25) J. R. Frade and M. Cable: J. Am. Ceram. Soc., 75 (1992), 1949.

26) A. Khawam and D. R. Flanagan: J. Phys. Chem. B, 110 (2006), 17315.

27) O. Levenspiel: Chemical Reaction Engineering, John Wiley \& Sons, New York, (1999), 524.

28) A. G. Okunev, S. A. Shaurman, A. F. Danilyuk, Y. I. Aristov, G. Bergeret and A. Renouprez: J. Non-Cryst. Solids, 260 (1999), 21.

29) M. Fertani-Gmati and M. Jemal: Thermochim. Acta, 513 (2011), 43.

30) M. Fertani-Gmati, K. Brahim, I. Khattech and M. Jemal: Thermochim. Acta, 594 (2014), 58.

31) M. Deleuze, A. Goiffon, A. Ibanez and E. Philippot: J. Solid State Chem., 118 (1995), 254. 